\title{
Treatment with Immunotherapy and Other Systemic Therapies for Patients With Recessive Dystrophic Epidermolysis Bullosa and Cutaneous Squamous Cell Carcinoma. A Single Institution Experience
}

\section{Sara Martinez-Fdez} \\ Hospital Universitario La Paz \\ Lorena Ostios-Garcia \\ Hospital Universitario La Paz

\section{Rocio Maseda} \\ Hospital Universitario La Paz

\section{Raul De Lucas} \\ Hospital Universitario La Paz

\section{Beatriz Castelo} \\ Hospital Universitario La Paz
}

David Viñal ( $\nabla$ david.vinnal@estudiante.uam.es)

Hospital Universitario La Paz https://orcid.org/0000-0002-9905-3270

\section{Research}

Keywords: Cutaneous squamous cell carcinoma, recessive dystrophic epidermolysis bullosa, immunotherapy, neoplasms

Posted Date: August 23rd, 2021

DOI: https://doi.org/10.21203/rs.3.rs-395978/v2

License: (c) (i) This work is licensed under a Creative Commons Attribution 4.0 International License. Read Full License 


\section{Abstract}

Purpose. Cutaneous squamous cell carcinoma (CSCC) is a frequent complication in patients with recessive dystrophic epidermolysis bullosa (RDEB). Immunotherapy is a novel treatment approach for CSCC, however there is little experience in patients with RDEB.

Methods. We included all the patients with a molecular-confirmed diagnosis of RDEB and advanced CSCC treated with systemic therapy between November 1988 and January 2021.

Results. Five patients were treated with immunotherapy $(n=2)$, other systemic therapies $(n=2)$, or both $(n=1)$. The tolerability of immunotherapy was overall acceptable with no treatment-related serious adverse events. Radiological tumor response observed in one patient. The other patients were treated with a combination of chemotherapy and targeted therapy (EGFR inhibitors), with mixed tumor response. Median OS was 3 months (range, 1 to 11).

Conclusions: Patients with RDEB and advanced CSCC benefit from immunotherapy and do not experience unexpected toxicity.

\section{Background}

Cutaneous squamous cell carcinoma (CSCC) is the leading cause of death in patients with recessive dystrophic epidermolysis bullosa (RDEB), a rare and severe subtype of an inherited mechanobullous disease [1]. The management of CSCC in RDEB patients was updated in 2016, and for the advanced setting, radiotherapy and chemotherapy were the only available treatment options [2]. However, the little experience with these therapies, the unfavorable toxicity profile, and the poor efficacy outcomes left best supportive care as the best therapeutic alternative in most of these patients [3].

Immunotherapy has emerged as a new treatment option for patients with CSCC. Cemiplimab, an anti-PD1 antibody, showed a $47 \%$ response rate in the metastatic cohort of a single-arm phase 2 trial [4]. This trial led to the approval of this agent in the advanced setting. Although RDEB is not an autoimmune disease, concerns about skin toxicity and other immunemediated side effects may question the role of these agents for RDEB patients. Up to date, few case reports have reported promising results with immunotherapy in patients with RDEB [5-7]. Our aim is to report our experience with immunotherapy and other systemic therapies in patients with RDEB and CSCC.

\section{Results}

In total, 5 patients with RDEB and CSCC have been treated with immunotherapy $(n=2)$, other systemic therapies $(n=2)$, or both $(n=1)$ since November 1988 and January 2021 at our institution. Efficacy and safety results are summarized in Table 1. In our institution, we were authorized to use nivolumab and pembrolizumab, two anti-PD1 antibodies for compassionate use in two patients with RDEB and advanced CSCC. The tolerability was overall acceptable with no treatment-related serious adverse events. Radiological tumor response observed in one patient. The other patients were treated with a combination of chemotherapy and targeted therapy (EGFR inhibitors), with mixed tumor response. Patients experienced treatment-related serious adverse events, mainly myelotoxicity and febrile neutropenia. At the time of the data cut-off, the 5 patients have died. Median progression-free survival to the first systemic therapy was 3 months (range, 1 to 8 ) and median overall survival was 3 months (range, 1 to 11 ). 
Table 1

Efficacy and safety results of immunotherapy and other systemic therapies in patients with RDEB and CSCC treated at our institution. CSCC, cutaneous squamous cell carcinoma; CTCAE v5.0, Common Terminology Criteria for Adverse Events version 5.0; MSSA, methicillin-sensitive staphylococcus aureus; PD, progressive disease; PR, partial response; RDEB, recessive dystrophic epidermolysis bullosa; $\mathrm{SD}$, stable disease.

\begin{tabular}{|c|c|c|c|c|c|c|c|c|}
\hline & $\begin{array}{l}\text { Age, } \\
\text { years }\end{array}$ & Sex & $\begin{array}{l}\text { Site of } \\
\text { CSCC }\end{array}$ & Treatment & $\begin{array}{l}\text { Tumor } \\
\text { response }\end{array}$ & $\begin{array}{l}\text { PFS, } \\
\text { months }\end{array}$ & $\begin{array}{l}\text { OS, } \\
\text { months }\end{array}$ & $\begin{array}{l}\text { Adverse events } \\
\text { (CTCAE v5) }\end{array}$ \\
\hline $\begin{array}{l}\text { Case } \\
1\end{array}$ & 18 & Male & $\begin{array}{l}\text { Right hand } \\
+ \text { ipsilateral } \\
\text { axillary } \\
\text { lymph node }\end{array}$ & Nivolumab & - & 3 & 3 & $\begin{array}{l}\text { Subclinical } \\
\text { hypothyroidism }\end{array}$ \\
\hline $\begin{array}{l}\text { Case } \\
2\end{array}$ & 27 & Male & $\begin{array}{l}\text { Right ankle } \\
+ \\
\text { involvement } \\
\text { of the } \\
\text { underlying } \\
\text { bone }\end{array}$ & Pembrolizumab & PR & 3 & 3 & $\begin{array}{l}\text { Subclinical } \\
\text { hypothyroidism }\end{array}$ \\
\hline \multirow{4}{*}{$\begin{array}{l}\text { Case } \\
3\end{array}$} & \multirow[t]{4}{*}{32} & \multirow[t]{4}{*}{ Male } & \multirow{4}{*}{$\begin{array}{l}\text { Left feet + } \\
\text { inguinal } \\
\text { lymph } \\
\text { nodes, } \\
\text { infiltrating } \\
\text { soft tissue } \\
\text { and bone }\end{array}$} & \multirow{4}{*}{$\begin{array}{l}\text { 1) } \\
\text { Paclitaxel/cetuximab/RT } \\
\text { 2) Cisplatin/5FU } \\
\text { 3) Carboplatin/5FU }\end{array}$} & 1)PR & 1) 8 & \multirow[t]{4}{*}{11} & \multirow{2}{*}{$\begin{array}{l}\text { 1) Rash, } \\
\text { folliculitis } \mathrm{G} 1 \text {, } \\
\text { diarrhea } \mathrm{G} 1\end{array}$} \\
\hline & & & & & 2) - & 2) 1 & & \\
\hline & & & & & \multirow[t]{2}{*}{ 3) - } & \multirow[t]{2}{*}{ 3) 2} & & $\begin{array}{l}\text { 2) Febrile } \\
\text { neutropenia, } \\
\text { G3 anemia }\end{array}$ \\
\hline & & & & & & & & $\begin{array}{l}\text { 3) Septic } \\
\text { shock, G4 } \\
\text { pancytopenia }\end{array}$ \\
\hline \multirow{2}{*}{$\begin{array}{l}\text { Case } \\
4\end{array}$} & \multirow[t]{2}{*}{25} & \multirow[t]{2}{*}{ Male } & \multirow{2}{*}{$\begin{array}{l}\text { Multifocal. } \\
\text { Axillary + } \\
\text { inguinal left } \\
\text { lymph } \\
\text { nodes, } \\
\text { pleural, soft } \\
\text { tissue }\end{array}$} & 1) Cisplatin/docetaxel & 1) $S D$ & 1) 4 & \multirow[t]{2}{*}{7} & \multirow{2}{*}{$\begin{array}{l}\text { 1) MSSA } \\
\text { bacteraemia }\end{array}$} \\
\hline & & & & 2) Cetuximab/paclitaxel & 2)PD & 2) - & & \\
\hline $\begin{array}{l}\text { Case } \\
5\end{array}$ & 30 & Male & $\begin{array}{l}\text { Popliteal } \\
\text { and } \\
\text { inguinal } \\
\text { lymph } \\
\text { nodes }\end{array}$ & Cisplatin/5-fluorouracil & - & 1 & 1 & $\begin{array}{l}\text { Febrile } \\
\text { neutropenia, } \\
\text { G3 diarrhea } \\
\text { and G2 } \\
\text { cutaneous } \\
\text { toxicity }\end{array}$ \\
\hline
\end{tabular}

\section{Case 1}

Our first patient was an 18-year-old man with a well-differentiated CSCC in the back of the right hand and axillary lymph node involvement. We started therapy with paclitaxel and cetuximab. However, although, no grade 3/4 adverse events were observed, progressive disease was found after 3 months of treatment. He started on nivolumab (3mg/kg every 2 weeks) in November 2018. We found a 60\% PD-L1 expression on tumor tissue. The tolerance was overall good, with no skin toxicity, only subclinical hypothyroidism and grade 1 dry mouth were reported. We continued the treatment for 5 cycles, with clinically stable disease. However, the patient was admitted to the intensive care unit of a local hospital for respiratory failure in the context of Influenza A pneumonia, confirmed with RT-PCR, and died 5 days later in January 2019. No imaging technique was performed to assess tumor response.

\section{Case 2}

Our second patient was a 27-year-old man with severe generalized RDEB that in May 2020 was diagnosed with CSCC on his right ankle with involvement of the underlying bone. The patient did not want to have his limb amputated and started 
pembrolizumab $2 \mathrm{mg} / \mathrm{kg}$ every 3 weeks on May 2020. The tolerance of the treatment was good, with clinical improvement of the tumor (Fig. 1). Subclinical hypothyroidism was the only adverse effect reported with an adequate response to hormone replacement treatment. A PET-CT scan was performed after 3 cycles of pembrolizumab and showed a partial metabolic response in both the ankle and satellite lesions. However, the patient died in July 2020 due to massive tumoral bleeding during a cure.

\section{Case 3}

Our third patient is a 32-year-old man with history of esophageal dilation and multiple surgical intervention for syndactyly. Since 2011, he had multiple surgeries for CSCC in the left foot and left inguinal lymph nodes. In October 2014 a computed tomography (CT) scan revealed a necrotic mass that infiltrate adjacent muscle and bone. The patient started treatment with cetuximab, paclitaxel, and 5-days radiotherapy (total dose: 20Gy) to the inguinal mass. The treatment was well tolerated, only local skin dryness and cetuximab-related grade 1 papulo-pustulose skin toxicity was observed. Two months later, the patient developed sepsis of skin origin with isolation of methicillin-sensitive staphylococcus aureus. Subsequent CT scan reported partial response. In august 2015, the patient progressed and we changed therapy to cisplatin and 5-FU. He developed grade 3 anemia and febrile neutropenia with skin isolation of multi-resistant klebsiella pneumoniae. Few weeks later chemotherapy was restarted but in November 2015 the patient died due to septic shock and grade 4 pancytopenia.

\section{Case 4}

The fourth patient was diagnosed in 2013 at the age of 20 with an RDEB-related CSCC. After multiple surgeries, a PET-CT scan revealed multiple cutaneous and subcutaneous lesions with metastasis to bilateral axillary and inguinal lymph nodes, pleura and soft tissue (adjacent to L1 vertebrae). Due to the multifocal spread with high tumor burden, we started chemotherapy with cisplatin and docetaxel in June 2014. Unfortunately, after two months of treatment and progressive disease in the CT scan, the patient developed tumor-related severe hypercalcemia and sepsis of skin origin with cutaneous isolation of Pseudomonas aeruginosa and methicillin-resistant staphylococcus aureus. Therapy based on Cetuximab and paclitaxel was administered in an attempt to control hypercalcemia. However, the patient experienced a progressive clinical deterioration, and antineoplastic treatment was discontinued after a month of treatment. In November 2014 the patient died due to a severe hypercalcemia, sepsis and tumoral skin hemorrhage.

\section{Case 5}

The third case is a 30-year-old man with RDEB and a history of CSCC in the sole of the left foot since 2005. In November 2017 PET-CT scan revealed popliteal and inguinal lymph node progression. The patient declined amputation and treatment with systemic antineoplastic treatment with cisplatin/5-fluorouracil and cetuximab was offered. By that time, the patient had a low performance status and periodic red cell transfusion due to chronic anemia. Without a central venous catheter available, we started therapy with cisplatin, and docetaxel. The patient experienced febrile neutropenia, grade 3 diarrhea and grade 2 cutaneous toxicity that required hospitalization in another center. The patient presented a torpid evolution with clinical deterioration that led to the patient demise 33 days after the initiation of the therapy.

\section{Discussion}

When considering systemic therapy in patients with RDEB and CSCC, we have to face several important issues. First, life expectancy of patients with RDEB is more limited and performance status is hampered by the disease. Moreover, scars, healing wounds and blistering may difficult venous access and generate discomfort and pain. Anemia, malnutrition and difficult oral intake are other main issues that may interfere with treatment $(4,5)$. There is also a general concern about the toxicity and possible adverse events of systemic antineoplastic therapy, mainly skin toxicity, bacteremia and sepsis of skin origin. 
We report one of the largest single-institution cohort of patients with RDEB and CSCC treated with immunotherapy and other systemic therapies. Overall, we observed that chemotherapy and other targeted therapies had little success in tumor control and favored sepsis and myelotoxicity. Our results have also been observed by others. We only found in the literature 8 patients treated with chemotherapy and targeted therapy [9-14]. Antineoplastic agents administered included platins, methotrexate, taxanes, doxorubicin, gemcitabine, 5-fluorouracil and cetuximab. Partial responses have been reported with cisplatin and 5-FU, intraarterial methotrexate and cetuximab. Toxicity profile varies between agents; however, sepsis and systemic infection has been reported as mayor adverse events, with infection-related mortality in a significant percentage of the patients. Skin toxicity related to cetuximab, although reported, does not appear to be life threatening. Immunotherapy seems a promising treatment option in these patients as toxicity profile is manageable (mainly subclinical hypothyroidism) and induced tumor response in one of the two patients. Importantly, no unexpected toxicity was reported. Three recent case reports have also highlighted the efficacy and tolerability of immunotherapy in these patients, even with treatment for prolonged periods of time. We encourage to treat patients with RDEB and CSCC with immunotherapy as front-line therapy. Ongoing clinical trials in the adjuvant setting (NCT04428671) may offer new treatment strategies.

\section{Conclusion}

In conclusion, the treatment with anti-PD1 in patients with RDEB was associated with a mild toxicity profile and tumor response. We suggest treating advanced CSCC in RDEB with immunotherapy once local therapies are no longer an option.

\section{Methods}

In this retrospective report, we included all the patients with a molecular-confirmed diagnosis of RDEB treated with systemic therapy between November 1988 and January 2021 at Hospital Universitario La Paz. Results of our whole cohort of patients with RDEB and CSCC have been previously reported [8], and include preliminary results of 4 patients of the present cohort. Adverse drug reactions were defined according to the Common Terminology Criteria for Adverse Events version 5.0 (CTCAE v5.0). Systematic research of literature was performed using "epidermolysis bullosa" and "cutaneous squamous" in Pubmed. This report was approved by the Ethics Committee of the La Paz University Hospital. were carried out using SPSS v.25.

\section{Declarations}

Ethics approval and consent to participate: This study was approved by the Ethics Committee of the La Paz University Hospital. This article does not contain any studies with animals performed by any of the authors. We confirm that all research was performed in accordance with relevant guidelines/regulations, informed consent was obtained from all participants and/or their legal guardians. The study has been performed in accordance with the Declaration of Helsinki.

Consent for publication: consent for publication was obtained from participants

Availability of data and materials: The datasets analysed during the current study are not publicly available but are available from the corresponding author on reasonable request.

Competing interests: The authors declare that they have no conflict of interest.

Acknowledgement and Funding: This work has not been supported by public grants or financial support. No sources of funding were used to assist in the preparation of this manuscript.

Authors' contributions: Conceptualization: David Viñal; Data collection: David Viñal, Sara Martinez Fdez; Data analysis: David Viñal; Writing - original draft preparation: David Viñal, Sara Martinez Fdez; Writing - review and editing: Lorena Ostios, Rocio Maseda; Supervision: Raul de Lucas, Beatriz Castelo. 


\section{References}

1. Fine JD1, Johnson LB, Weiner M, Li KP, Suchindran C. Epidermolysis bullosa and the risk of life-threatening cancers: the National EB Registry experience, 1986-2006. J Am Acad Dermatol. 2009;60(2):203-11.

2. Mellerio JE, Robertson SJ, Bernardis C, Diem A, Fine JD, George R, et al. Management of cutaneous squamous cell carcinoma in patients with epidermolysis bullosa: best clinical practice guidelines. Br J Dermatol Jan. 2016;174(1):5667.

3. Castelo B, Viñal D, Maseda R. Epidemiology and natural history of cutaneous squamous cell carcinoma in recessive dystrophic epidermolysis bullosa patients: 20 years' experience of a reference centre in Spain. Clin Transl Oncol. 2019 Nov;21(11):1573-7. doi:10.1007/s12094-019-02073-3. Epub 2019 Mar 12.

4. Migden MR, Rischin D, Schmults CD, et al (2018) PD-1 Blockade with Cemiplimab in Advanced Cutaneous SquamousCell Carcinoma. N Engl J Med. 26;379(4):341-351.

5. Duong T, Wong D, Barrett A, Price H. Successful use of immunotherapy to treat advanced cutaneous squamous cell carcinoma in recessive dystrophic epidermolysis bullosa. BMJ Case Rep. 2021;14(2):e238966. doi:10.1136/bcr-2020238966. Published 2021 Feb 26.

6. Khaddour K, Gorell ES, Dehdashti F, Tang JY, Ansstas G. Induced Remission of Metastatic Squamous Cell Carcinoma with an Immune Checkpoint Inhibitor in a Patient with Recessive Dystrophic Epidermolysis Bullosa. Case Rep Oncol. 2020;13(2):911-5. doi:10.1159/000508933. Published 2020 Jul 30.

7. Piccerillo A, El Hachem M, De Vito R, De Luca EV, Peris K. Pembrolizumab for Treatment of a Patient With Multiple Cutaneous Squamous Cell Carcinomas and Recessive Dystrophic Epidermolysis Bullosa. JAMA Dermatol. 2020;156(6):708-10. doi:10.1001/jamadermatol.2020.0304.

8. Castelo B, Viñal D, Maseda R, et al. Epidemiology and natural history of cutaneous squamous cell carcinoma in recessive dystrophic epidermolysis bullosa patients: 20 years' experience of a reference centre in Spain. Clin Transl Oncol. 2019;21(11):1573-7. doi:10.1007/s12094-019-02073-3.

9. Kim M, Li M, Intong LRA, Tran K, Melbourne W, Marucci D, et al. Use of cetuximab as an adjuvant agent to radiotherapy and surgery in recessive dystrophic epidermolysis bullosa with squamous cell carcinoma. $\mathrm{Br} \mathrm{J}$ Dermatol. 2013;169:208-10.

10. Arnold AW, Bruckner-Tuderman L, Zuger C, Itin PH. Cetuximab therapy of metastasizing cutaneous squamous cell carcinoma in a patient with severe recessive dystrophic epidermolysis bullosa. Dermatology. 2009;219:80-3.

11. Schwartz RA, Birnkrant AP, Rubenstein DJ, Kim U, Burgess GH, Stoll HL, et al. Squamous cell carcinoma in dominant type epidermolysis bullosa dystrophica. Cancer. 1981;47:615-20.

12. Lentz SR, Raish RJ, Orlowski EP, Marion JM. Squamous cell carcinoma in epidermolysis bullosa. Treatment with systemic chemotherapy. Cancer. 1990;66:1276-78.

13. Wechsler HL, Krugh FJ, Domonkos AN. Polydysplastic epidermolysis bullosa and deelopment of epidermal neoplasms. Arch Dermatol. 1970 Oct;102(4):374-80.

14. Mallipeddi R. Epidermolysis bullosa and cancer. Clin Exp Dermatol. 2002 Nov;27(8):616-23.

\section{Figures}



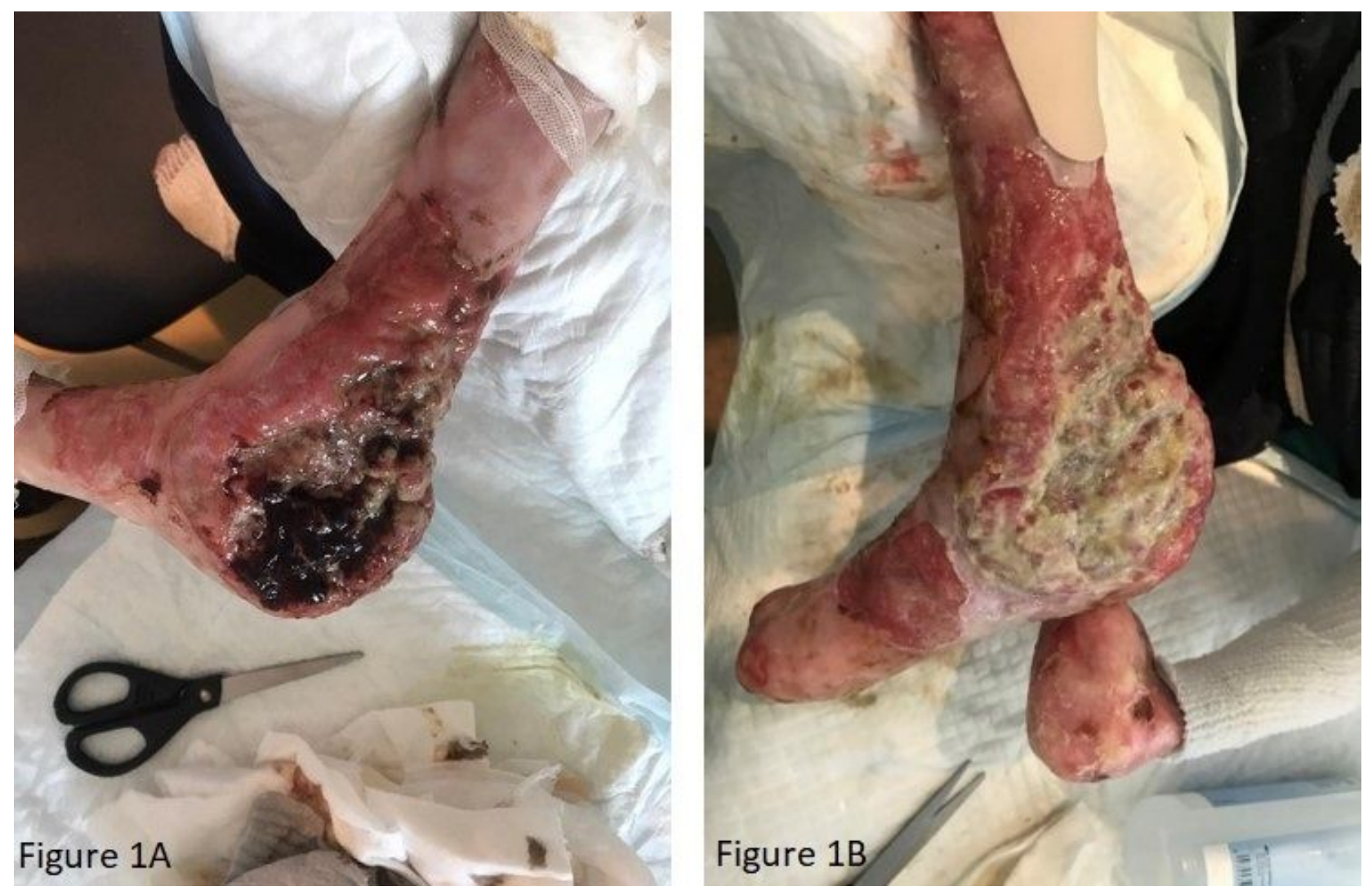

\section{Figure 1}

Cutaneous squamous cell carcinoma of the ankle in patient 2. Figure 1A: before pembrolizumab. Figure 1B: after one dose of pembrolizumab. 